\title{
An Updated Review of the Fatigue Behavior of Components Coated with Thin Hard Corrosion-Resistant Coatings
}

\author{
Sergio Baragetti ${ }^{*}, 1,2$ and Francesco Villa ${ }^{1}$ \\ ${ }^{I}$ Department of Engineering, University of Bergamo, Viale Marconi 5, Dalmine 24044, Italy \\ ${ }^{2}$ GITT - Centre on Innovation Management and Technology Transfer, University of Bergamo, Via Salvecchio 19, \\ Bergamo 24129, Italy
}

\begin{abstract}
In the present manuscript, an extended review on the state of the art on the experimental and numerical characterization of the fatigue behavior of Physically Vapor Deposited (PVD) and Chemically Vapor Deposited (CVD) thin hard coatings is presented. The current application and development fields of PVD and CVD treatments are analysed, focusing on the advantages granted by the adoption of these coatings for corrosion protection on various materials and components. The most recent experimental research results related to the fatigue behavior of PVD and CVD coated specimens are reported. Fatigue strength values are presented for various coating processes on different substrates, including hard steel as well as aluminium and titanium light alloys. Corrosion fatigue effects on coated specimens are presented where available, in order to evaluate the coating effectiveness in aggressive environments. An overview on the current state of development of theoretical and numerical models for the characterization of coated components and for the maximum number of cycles to failure is proposed to the reader.
\end{abstract}

Keywords: Corrosion-fatigue, fatigue, residual stresses, theoretical-numerical models, thin hard coatings.

\section{INTRODUCTION}

The present work contains an extended and updated version of a previous review by Baragetti et al. (2011) [1]. New literature has been added, particularly regarding Physical Vapor Deposition (PVD) and Chemical Vapor Deposition (CVD) application fields and new experimental results, thus giving the reader an enhanced view of the possibilities and the issues related to the adoption of these surface treatments over different substrates. The most typical applications of thin hard coatings include protection of cutting tools, cold and hot stamping and extrusion dies [2-4], due to the improvement in surface performance granted by these coatings in terms of hardness, wear and corrosion resistance properties [5-12]. Thin hard coatings can have a positive influence on the fatigue and the corrosion fatigue behavior of mechanical components, especially for relatively hard steel substrates [13-23]. For these reasons, PVD and CVD coatings are nowadays adopted also for other advanced applications in addition to manufacturing, including but not limited to automotive components [24-28], aeronautic gas engines turbine and compressor blade protection $[29,30]$ and biomedical applications, due to the improved corrosion protection and biocompatibility granted by thin hard coatings [31].

For an efficient adoption of thin hard coatings in the design of mechanical components subjected to aggressive environments, a suitable characterization of the fatigue

*Address correspondence to this author at the Department of Engineering, University of Bergamo, Viale Marconi 5, Dalmine 24044, Italy;

Tel: 0039-035-2052382; E-mail: sergio.baragetti@unibg.it properties of the coating-substrate ensemble must be carried out. Different contributions can affect the fatigue resistance of PVD and CVD coated components. Compressive residual stresses introduced by the deposition process often produce a beneficial effect on the fatigue behavior of coated components [17, 18, 32, 33], although their advantage can be reduced by the microstructural modifications induced in the substrate material by the high temperatures typical of these processes [34], especially when light alloys are considered. The fatigue characteristics of coated aluminium and titanium alloys deserve indeed increased attention, since the positive effects which are often found on harder substrates must not be taken for granted on these materials [34-42]. Despite of this aspect, the adoption of PVD and CVD coatings over these high strength-to-mass ratio alloys is crucial to grant new application fields to these materials, which are becoming critical in the design of lightweight and efficient vehicles and mechanical devices. In this review paper, the most recent experimental results related to fatigue and corrosion fatigue behavior on steel [13-23] and light alloy [34-42] substrates are presented, giving some precious indications to mechanical designers about possible trends of the fatigue and corrosion fatigue behavior of different substrate/coating couplings.

Considering the theoretical and numerical modelling of coated components, a few literature references have been found, compatibly with the actual state of the art in the field $[17,18,42-49]$. A significant portion of these works, i.e. [4649], is limited to coating characterization, while only a few of the other literature sources try to dig deep in theoretical and numerical procedures to predict the crack propagation and fatigue life of the coated component, including the 
coating and substrate ensemble [17, 18]. These models actually proved good agreement with experimental data, and they were successfully extended to predict also contact fatigue behavior of PVD coated AISI 3415 and Ti-6Al-4V racing motorcycles spur gears [43-45], thus defining a starting point for the numerical simulation of crack propagation and fatigue effects of thin coated components. By looking at the actual situation, the development of numerical tools for the prediction of fatigue life of PVD and CVD coated components is still a challenge to be faced by researchers and mechanical designers.

\section{EXPERIMENTAL RESULTS}

In the present section, an extended collection of literature data related to the most recent experimental results on fatigue behavior of thin coated steel and light alloy materials is provided, including corrosion fatigue effects where available. The results, summarized in Table 1, represent an extension of the analysis presented in [1], including most recent developments which were not traceable at the publication times of [1].

\subsection{Fatigue Behavior of Thin Hard-Coated Steel Alloys}

The fatigue behavior of coated tool and stainless steels has been particularly studied because the anti-corrosion and wear properties of the layers suit the requirements of the applications which these base materials are largely used for. Some studies on other structural steel alloys can also be found.

In [13], Guu and Hocheng studied the fatigue behavior of TiN-coated EDM AISI D2 tool steel samples. Excellent coating adhesion and high surface hardness coupled with a slightly decreased surface roughness were pointed out for the coated material. Remarkable improvements in the bending fatigue life from 10.9 to $29.4 \%$ depending on the machining parameters were found (Table 1). The residual compressive stresses induced by the deposition process were supposed to have compensated the detrimental tensile stresses left by the EDM process on the machined surfaces.

Puchi-Cabrera et al. investigated the rotating bending fatigue behavior of $316 \mathrm{~L}$ stainless steel coated with different thin films [14, 15]. In [14], TiN was deposited on 316L samples to evaluate their fatigue behavior in comparison with that of uncoated samples. The fatigue limit of the coated material at $5 \times 10^{6}$ load cycles was increased by $22 \%$ (Table 1). SEM observations of the fracture surfaces highlighted that TiN had delaminated at high alternating stresses (Fig. 1). Compressive residual stresses of about 7.08 GPa were XRD-detected in the coating and were believed to be the main reason behind the improved fatigue behavior of the coated samples. Fatigue cracks nucleated at the sample surface and propagated either towards the sample's core or along the coating-substrate interface. It was concluded that the deposition of TiN to enhance the anti-corrosion, -galling and -wear properties of $316 \mathrm{~L}$ is also effective in improving its fatigue properties. Supported by these results, in [15] the fatigue behavior of $316 \mathrm{~L}$ coated with a different and very hard DLC (Diamond Like Carbon) film deposited by PVD magnetron sputter ion plating was studied. In this case the tests were carried out both in air and in $3 \mathrm{wt} \% \mathrm{NaCl}$ solution. The coating was beneficial to the fatigue behavior of the base material, particularly under corrosive conditions.

(a)

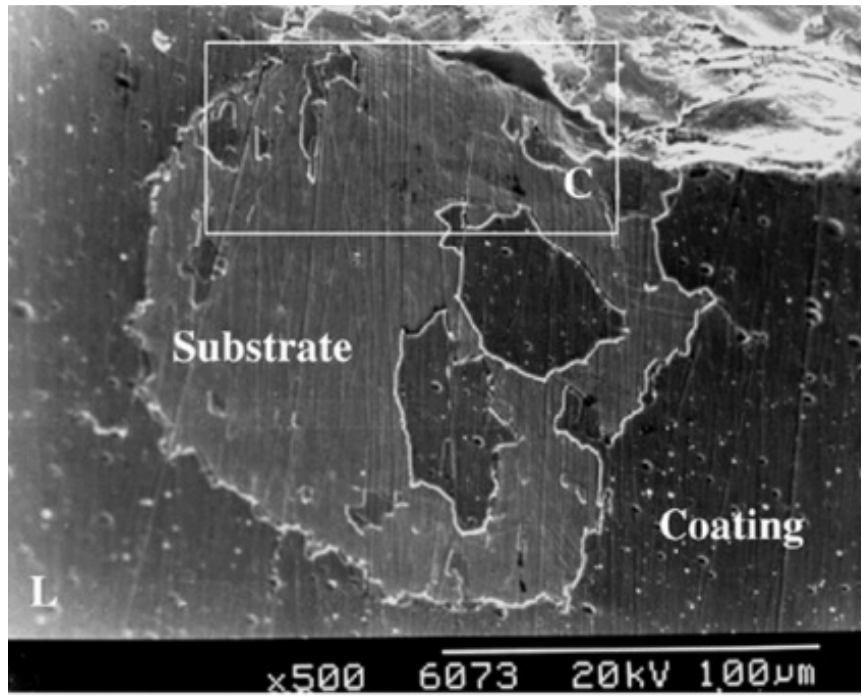

(b)

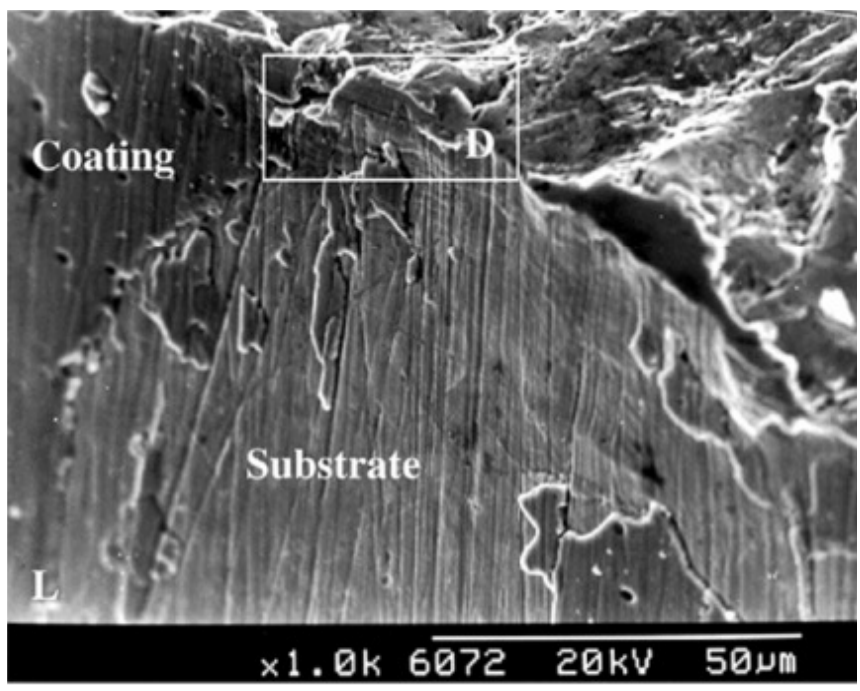

Fig. (1). (a) Lateral wall of a TiN-coated $316 \mathrm{~L}$ sample failed at an alternating stress of $510 \mathrm{MPa}$. The coating delamination could have been promoted from the crack initiation site. (b) Magnification of the area depicted as C in Fig. (1a) [14].

The fatigue limit at $5 \times 10^{6}$ load cycles in the presence of the coating was increased by more than $7 \%$ and $27 \%$ in air and in $\mathrm{NaCl}$ solution respectively (Table 1). The improved corrosion-fatigue behavior was believed to have been strongly related to the amorphous nature of the hydrogenated carbon layer deposited onto the crystalline $\mathrm{Cr}-\mathrm{C}$ layer in contact with the steel substrate. Furthermore, the high mechanical strength of the coating, the possible residual compressive stresses in the surface layers of the coated samples and the good coating adhesion were all supposed to have contributed to the overall increase in the fatigue performances of the coated samples. The remarkable results achieved in corrosive medium must be underlined and new experiments on different base materials coated with DLC should be addressed to check the potentials of the coatings from this point of view. 
In [16], the influence of Deep Cryogenic Treatment (DCT) and PVD CrN coating on the fatigue behavior of AISI 302 stainless steel was studied by considering the effects of the single treatments and of their combination. The $\mathrm{CrN}$ coating improved the fatigue resistance of the base material significantly (Table 1). Possible surface residual compressive stresses introduced by the PVD deposition process were supposed to have mainly contributed to this improvement. By contrast, the additional DCT treatment after coating deposition did not produce any significant further improvement confirming the higher effectiveness of the PVD process.

Both stainless and tool steels were studied by Baragetti et al. in $[17,18]$. Four-point bending tests were carried out on uncoated and PVD CrN-coated 2205 stainless steel and H11 tool steel samples (Table 1). X-ray measurements were performed to detect the surface residual stresses which fell in the range -1.5 to $-1.7 \mathrm{GPa}$ in the coated 2205 samples and were higher than $-2.4 \mathrm{GPa}$ in the coated $\mathrm{H} 11$ ones. As highlighted by the numerical data reported in Table 1, remarkable outcomes were observed for both the H11 and the 2205 samples with fatigue strength increases between $15 \%$ and $16 \%$.

Studies on coated high strength structural steel alloys were also addressed by researchers. In [19], $\mathrm{SiO}_{x}$ was deposited on quenched and tempered $39 \mathrm{NiCrMo} 3$ steel samples by plasma enhanced-CVD (PE-CVD). The samples were tested under rotating bending in laboratory air at room temperature. Negligible residual stresses were believed to have been generated by the low deposition temperature of the PE-CVD process. Accordingly, fatigue cracks nucleated on the external surface (Fig. 2). As reported in Table 1, the coating was somewhat detrimental to the fatigue resistance of the base material. Scratch tests showed some coating elasticity and acceptable coating-substrate adhesion. Based on the relatively limited worsening of the fatigue resistance, the deposition of $\mathrm{SiO}_{x}$ on steel could prove effective for applications requiring high resistance to scratch and corrosion and involving relevant fatigue loads.

Table 1. Literature results from fatigue tests on different coatings and base materials, integrated from [1].

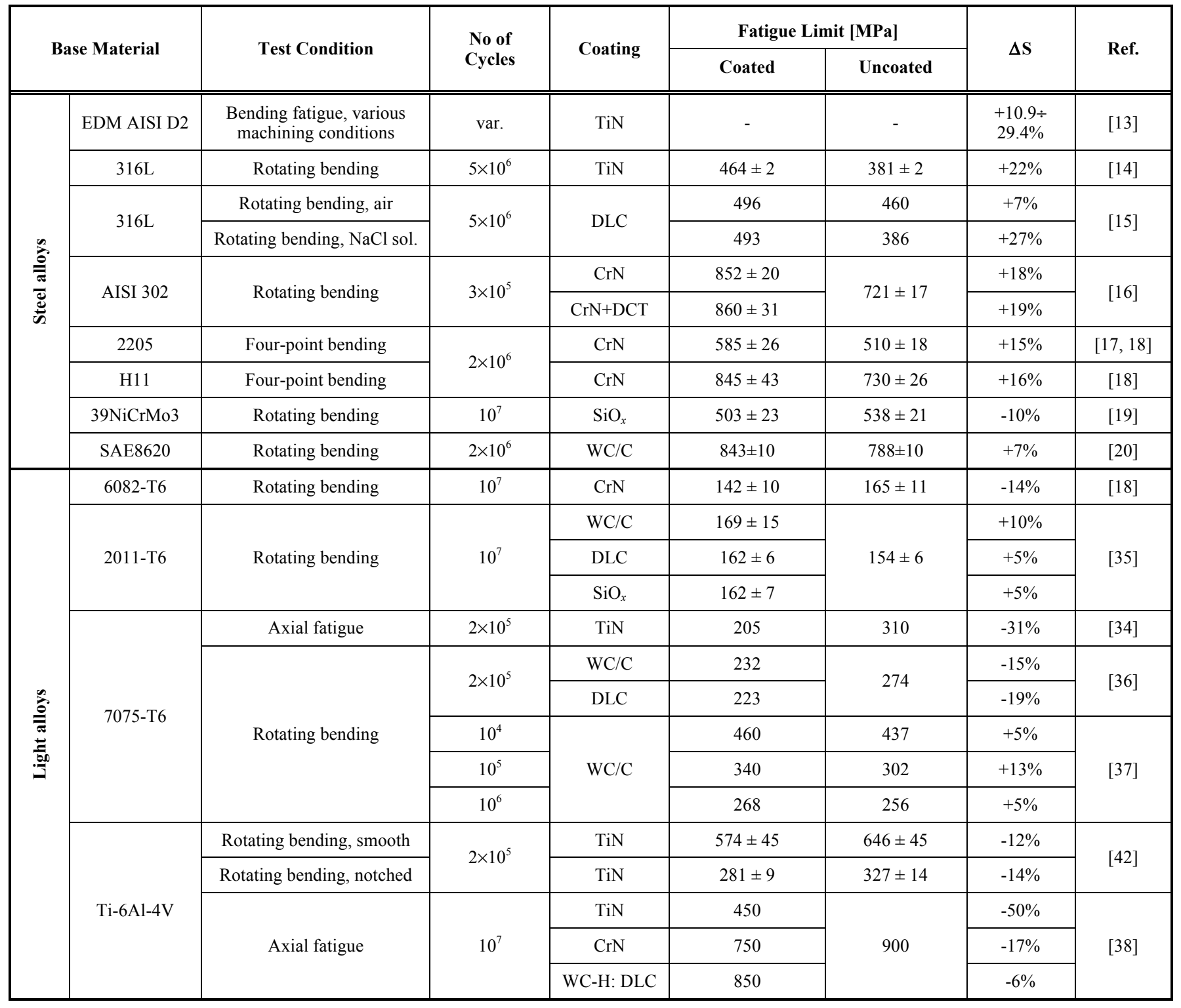


(a)

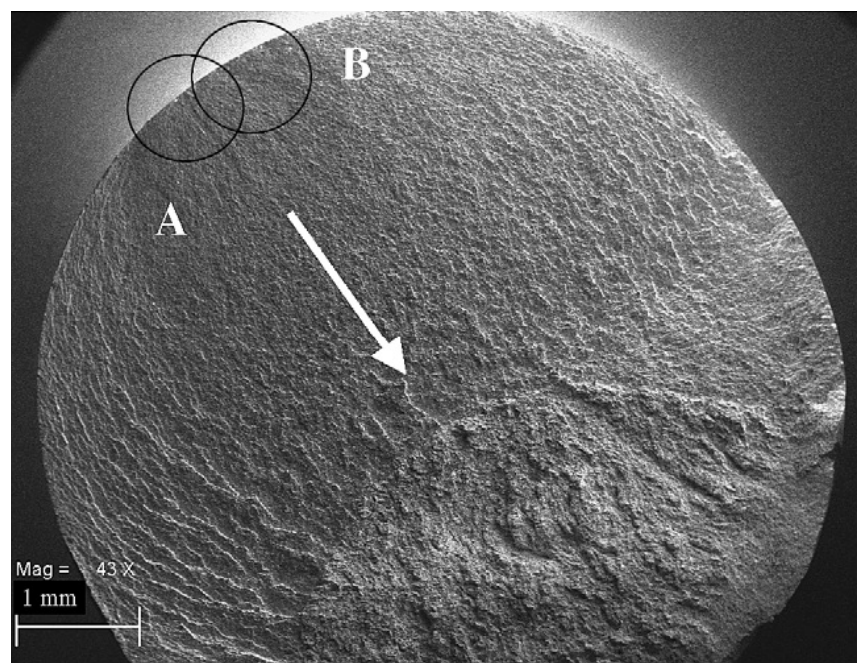

(b)

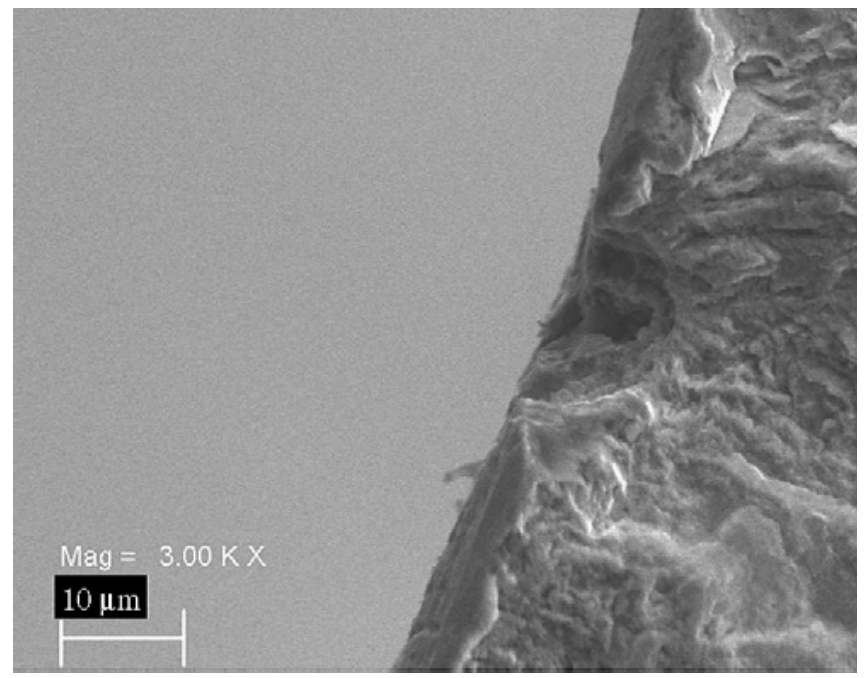

Fig. (2). (a) Fracture surface overview of a $\mathrm{SiO}_{x}$-coated $39 \mathrm{NiCrMo} 3$ sample and (b) higher magnification of the crack initiation site depicted as B in Fig. (2a) [19].
A wide testing campaign was conducted by Saini and Gupta over WC/C PVD coated case carburized SAE8620 steel, in [20]. This high performances steel, typically adopted in the automotive industry for gears and crankshafts, is the ideal candidate for the surface enhancement granted by the $\mathrm{WC} / \mathrm{C}$ treatment. The endurance limits found in this case, determined for cycles over $2 \times 10^{6}$, were of $788 \mathrm{MPa}$ for the uncoated, case carburized steel, and of $843 \mathrm{MPa}$ for the $\mathrm{WC} / \mathrm{C}$ coated specimens. A great portion of the detected increase of the fatigue life with respect to the green material (endurance limit of $249 \mathrm{MPa}$ ) was mainly granted by the residual compressive stresses generated in the case carburization process. The $\mathrm{WC} / \mathrm{C}$ coating however succeeded in increasing the value of the residual stresses, and thus improving the fatigue performance of SAE8620 steel. A share of this beneficial behavior may be derived from the low deposition temperatures associated with the $\mathrm{WC} / \mathrm{C}$ process, which may reach a maximum of $220^{\circ} \mathrm{C}$, leading to a minor substrate modification. The authors also performed several rotating bending fatigue strength tests at different values of the maximum applied stresses, thus identifying a preliminary S-N curve (Fig. 3). It is interesting to underline that, for high fatigue strengths, corresponding to lowcycle fatigue, the presence of the $\mathrm{WC} / \mathrm{C}$ coating actually decreases the fatigue performances with respect to the uncoated substrate. The authors of [20] identify the generation of multiple cracks in the coating, caused by the deflection reached at high maximum stresses, as the main cause of this behavior.

Another structural steel alloy, say quenched and tempered 4140, coated with thin hard low friction $\mathrm{Cr}$ coating was studied in [21]. Rotating bending tests carried out at different alternating stresses showed that both the fatigue life and fatigue limit of the coated samples were significantly reduced in comparison with the uncoated ones, i.e. by up to $88 \%$ and $21 \%$ respectively. Despite SEM observations showed that the coating remained well adherent to the substrate during the fatigue tests, multiple crack initiation sites at the substrate-deposit interface were observed (Fig. 4). This suggested that the coating had acted as a crack source for the steel substrate making the use of $\mathrm{Cr}$ coated 4140 steel potentially critical for structural applications involving high numbers of load cycles.

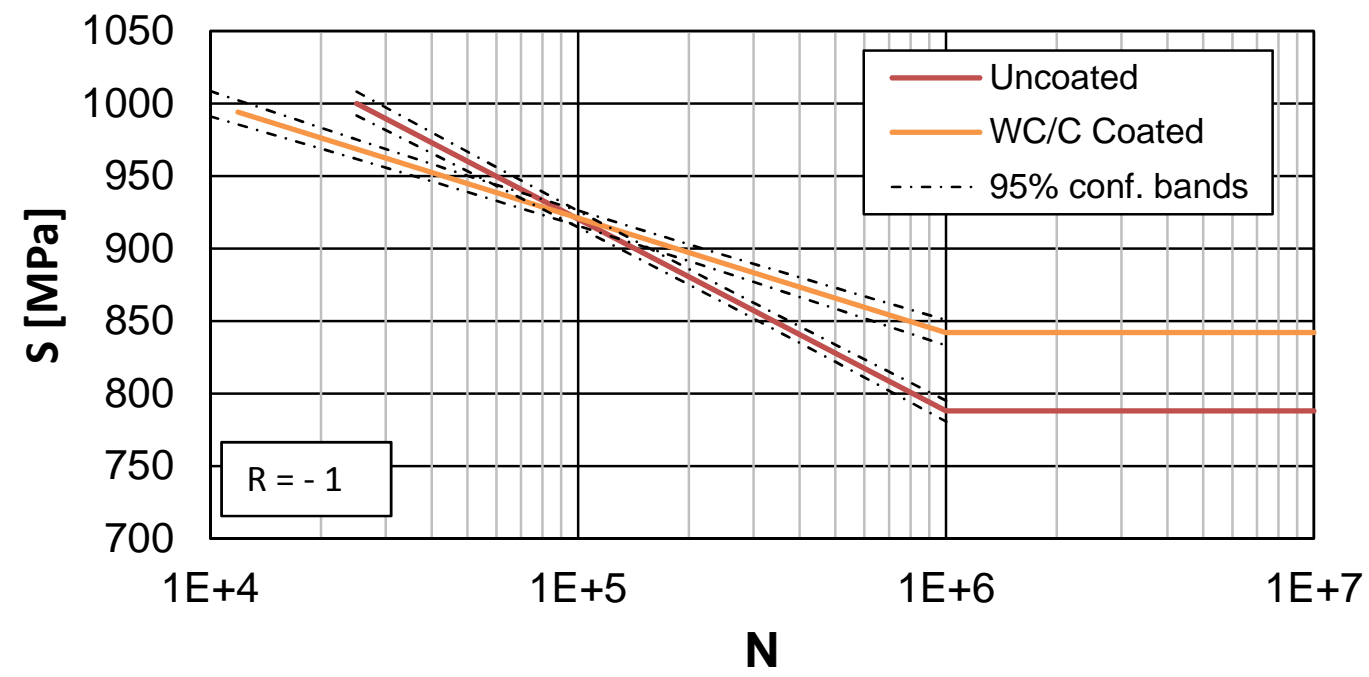

Fig. (3). S-N graphs for uncoated and WC/C coated case carburized SAE8620 steel specimens, obtained from data presented in [20]. 


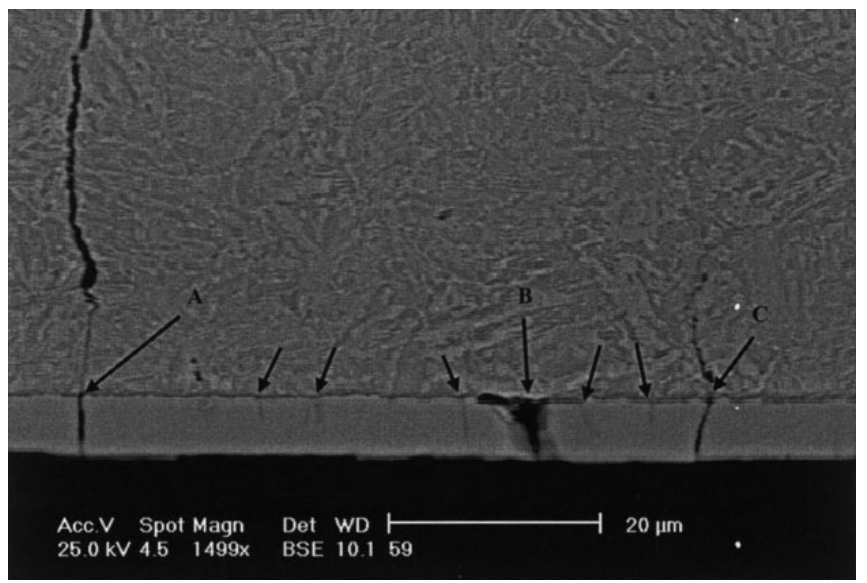

Fig. (4). Detail of the substrate-coating interface area of a sample tested at an alternating stress of $563 \mathrm{MPa}$ showing several coating fractures acting like crack initiation sites for the base material [21].

$\mathrm{Cr}-\mathrm{Mo}-\mathrm{V}$ steels used for high temperature steam turbine rotor components have been found to be base materials which can take advantage of coating deposition. The effects of wear-protective, heat-resistant and corrosive-resistant thin hard ceramic coatings on the fatigue behavior of steels were examined in [22, 23]. In [22], Kim et al. characterized the mechanical properties of TiN, TiCN and TiAlN deposited by arc ion plating on $\mathrm{Cr}-\mathrm{Mo}-\mathrm{V}$ steel and carried out both rotating bending tests and axial constant amplitude loading tests on CT samples up to high cycle fatigue lives. Good adhesion to the substrate was found and high compressive residual stresses from crystal growth were produced in the coating layers. The fatigue strengths of the coated samples were higher, especially at long fatigue lives, for all the coating thickness investigated. It was believed that the fatigue strength improvement of the coated material was mainly due to the constraint of plastic deformation of the substrate by hard coating layer and high compressive residual stresses. Furthermore, the fatigue crack growth rates observed were not altered over the full range of $\Delta K$ by the coating presence regardless of the thickness. The high temperature effect was accounted for in [23] by Suh et al. who investigated the rotating bending fatigue resistance of $1 \mathrm{Cr}-1 \mathrm{Mo}-0.25 \mathrm{~V}$ steel coated with PVD TiN and TiAlN coatings. Particularly, the tests on the TiAlN-coated samples were carried out at both room and high temperature. Good results were observed at room temperature because of the high surface residual compressive stresses that were detected by XRD, whereas the fatigue strength dramatically decreased at $400{ }^{\circ} \mathrm{C}$ and $538{ }^{\circ} \mathrm{C}$. Such behavior was associated with the residual stresses relief in the coating resulting from the temperature increase. This clearly represents a serious problem to face with further research studies to allow larger and larger use of these coatings in high temperature applications.

From the review of the experimental studies on thin hardcoated steel alloys reported in this section, it can be remarked that the fatigue behavior of steel alloys when coated with thin hard wear- and corrosion-resistant coatings has not been studied enough yet. In fact, although encouraging and sometimes remarkable results have been collected both in air and in corrosive medium, too few authors have devoted their research interest on this subject.
In fact, the range of base materials and coatings investigated up until now should be broadened to achieve the optimization of the performances of the coated components. The design of suitable experiments to define the most effective combinations of coating and base material as well as the best adjustment of the deposition process parameters to maximize the mechanical properties of the coated components could be fundamental from this point of view.

If considering the results collected until now on coated steel substrates, TiN and CrN coatings have shown the best performances in terms of fatigue resistance. The residual compressive stresses generated by the coating deposition process were believed to be the main reason for the achieved improvements. These coatings have been applied successfully to both tool and stainless steels. However, the high deposition temperatures - which are largely responsible for the higher residual stresses induced - may prevent them from being used more extensively over a wider range of base materials.

It must be noted that low deposition temperature coatings, such as $\mathrm{WC} / \mathrm{C}$, have proven to be adequate for improving the fatigue characteristics of steel substrates, at least for the endurance limits. High stresses, typical of the fatigue region below $1 \times 10^{5}$ cycles, can lead however to premature multiple cracking of the coating, leading to a detrimental contribution to the fatigue performances.

In conclusion, the overall fatigue performances of coated steels are subjected to multiple factors, which can modify the effects on fatigue of the coatings. The most important parameters to choose a PVD or CVD coating, considering the literature work, have been identified as the specific coating-substrate matching, the substrate surface properties, and the thermal load during the thin coating deposition process, which may affect the substrate properties and hence the fatigue life limit, in terms of cycles number, desired for the material.

\subsection{Fatigue Behavior of Thin Hard-Coated Light Alloys}

Notwithstanding aluminium and titanium alloys are the main light metal alloys used for structural applications, their fatigue behavior in the presence of a coating has not been studied as much as it has been done for steel alloys. In fact, only few references can be found in the literature.

In [18], rotating bending tests on PVD CrN-coated 6082T6 aluminium samples were carried without finding good results for the fatigue resistance of the base material (Table 1). The ineffectiveness of the coating was due to its impossibility to sustain the strains imposed to the overaged aluminium base material. This led to multiple cracking of the coating.

In [35], 2011-T6 aluminium alloy was PVD- and CVDcoated with $\mathrm{WC} / \mathrm{C}, \mathrm{DLC}$ and $\mathrm{SiO}_{x}$ films. Rotating bending tests on coated and uncoated samples were carried out in laboratory air at room temperature. The best results were found for the $\mathrm{WC} / \mathrm{C}$ coating - the average value of the limiting alternating stress of the coated samples at $10^{7}$ load cycles was increased by $10 \%$ (Table 1). Subsurface crack initiation, observed on WC/C-coated 2011-T6 sample fracture surfaces (Fig. 5a), was associated with the presence 
of possible residual compressive stresses preventing crack nucleation on the external surface. The good adhesion shown by the coating (Fig. 5b) was also supposed to have contributed to the fatigue resistance improvement.

(a)

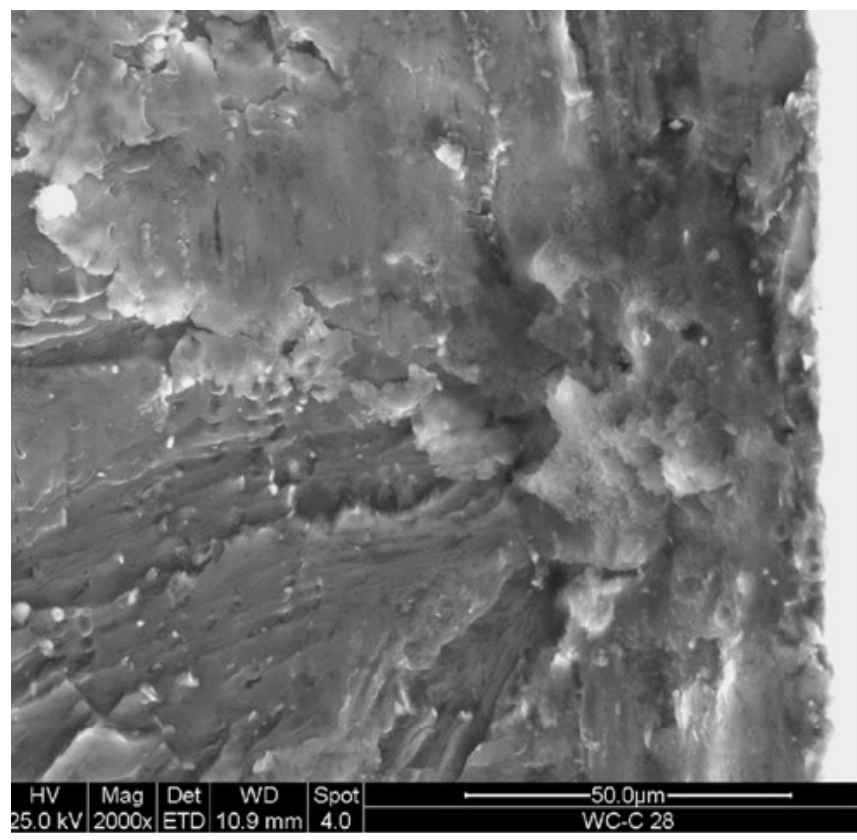

(b)

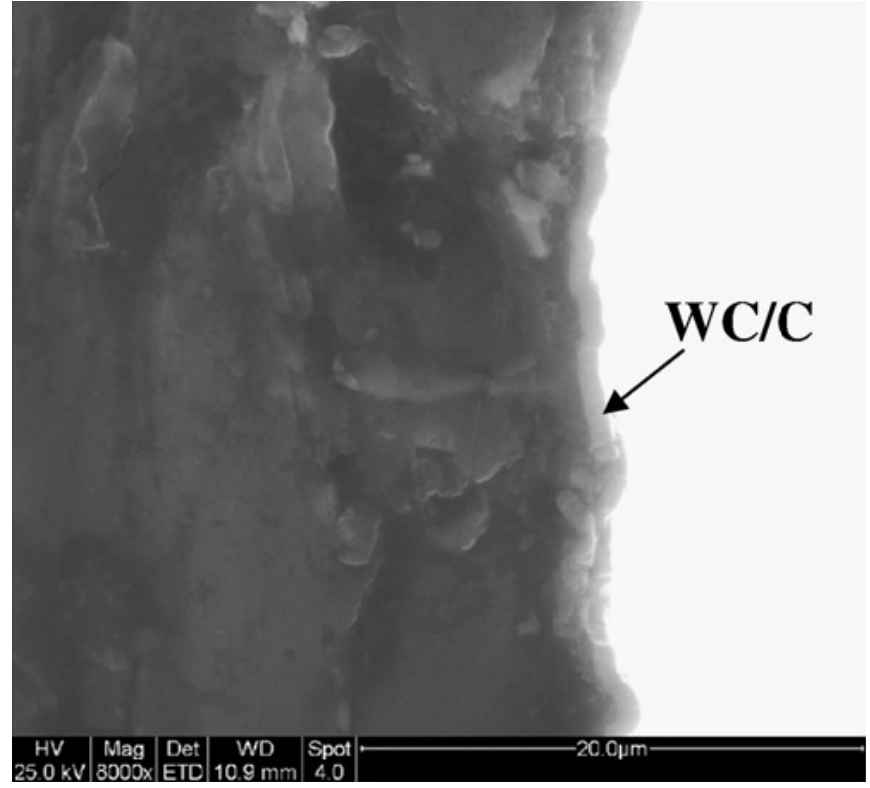

Fig. (5). (a) Magnification of the crack nucleation site of a 2011-T6 WC/C-coated sample tested at $190 \mathrm{MPa}$ and failed after 890,178 cycles, showing the subsurface initiation and (b) higher magnification in the vicinity of the external surface [35].

Further studies of the fatigue behavior of low deposition temperature $\left(180{ }^{\circ} \mathrm{C}\right) \mathrm{WC} / \mathrm{C}$ and DLC coated specimens have been carried on in [36]. Results from step-loading rotating bending fatigue testing of $\mathrm{WC} / \mathrm{C}$ coated 7075-T6 specimens at $2 \times 10^{5}$ cycles showed a reduction of fatigue life, with respect to the uncoated materials, of $-15 \%$ to $-19 \%$ of the maximum bending stress. Polished and uncoated specimens, which were subjected to the same thermal loads of $\mathrm{WC} / \mathrm{C}$ and DLC PVD coating processes, showed that a significant portion of the loss in terms of maximum stress was imputable to the heat received in the process, in terms of a $40 \%$ for $\mathrm{WC} / \mathrm{C}$ and $95 \%$ for DLC.

In another work on rotating bending fatigue of $\mathrm{WC} / \mathrm{C}$ coated 7075-T6 specimens, a positive fatigue behavior of the coating was found, showing a $8 \%$ mean increment in fatigue strength from $1 \times 10^{4}$ to $1 \times 10^{6}$ cycles [37]. The improved effectiveness in this coating in this case may be ought to differences in the PVD coating cycle and in the specimens surface finishing, stressing the high sensitivity of the fatigue behavior of PVD coated light alloys to the deposition parameters and conditions. The work highlighted also a reduction of fatigue strength after damaging the specimens either before $(-11 \%)$ and after $(-29 \%)$ the deposition of the $\mathrm{WC} / \mathrm{C}$ layer. Uncoated damaged specimens showed an average decrease of $18 \%$ in terms of limiting bending stress.

The effects on the axial fatigue behavior $(R=0.1)$ of 7075-T6 aluminium with TiN PVD coating was tested in the work of Oskouei and Ibrahim [34]. The high deposition temperature, reaching a maximum of $450{ }^{\circ} \mathrm{C}$ during the coating deposition, completely disrupted the characteristics of the T6 temper, which presents a $121{ }^{\circ} \mathrm{C}$ ageing temperature, leading to a reduction of the maximum axial fatigue stress of approximately $-31 \%$ at $2 \times 10^{5}$ cycles. A similar loss is encountered from $1 \times 10^{4}$ to $1 \times 10^{6}$ cycles. The Authors propose a post heat treatment, which partially recovers the fatigue characteristics of the TiN coated 7075T6 alloy, at least for maximum fatigue strengths at less than $1 \times 10^{5}$ cycles.

A significant reduction in both the static and the fatigue resistance of 7075-T6 aluminium alloy was also observed by depositing a high temperature (above $400{ }^{\circ} \mathrm{C}$ ) PVD $\mathrm{ZrN}$ coating [39]. Nevertheless, the least negative results were found under corrosive conditions and low alternating stresses: at maximum alternating stresses below $220 \mathrm{MPa}$ in $\mathrm{NaCl}$ solution the coated samples showed performances similar to those of the uncoated ones. In fact, the coating remained well adherent to the base material protecting it from the corrosive medium.

By contrast, in [40] good results for the fatigue and the corrosion-fatigue behavior of 7075-T6 coated with an electroless Ni-P (EN) deposit were found. It was remarked that under corrosive condition, say in $3 \mathrm{wt} \% \mathrm{NaCl}$ solution, the amorphous structure of the coating was effective against pitting and multiple fatigue crack nucleation. Increments not lower than $55 \%$ in the fatigue life of the tested samples were produced. Nodular defects present on the surface of the coated samples were observed to be associated with fatigue crack nucleation sites, particularly at high alternating stresses (Fig. 6). The very good adhesion, the high mechanical strength and possible compressive stresses in the coating were supposed to have had a very high influence on the improvements achieved in the fatigue behavior of the base material.

Studies on the fatigue behavior of coated titanium alloys are almost absent in the literature. In [42], the rotating bending fatigue behavior of TiN PVD-coated Ti-6Al-4V 
(a)

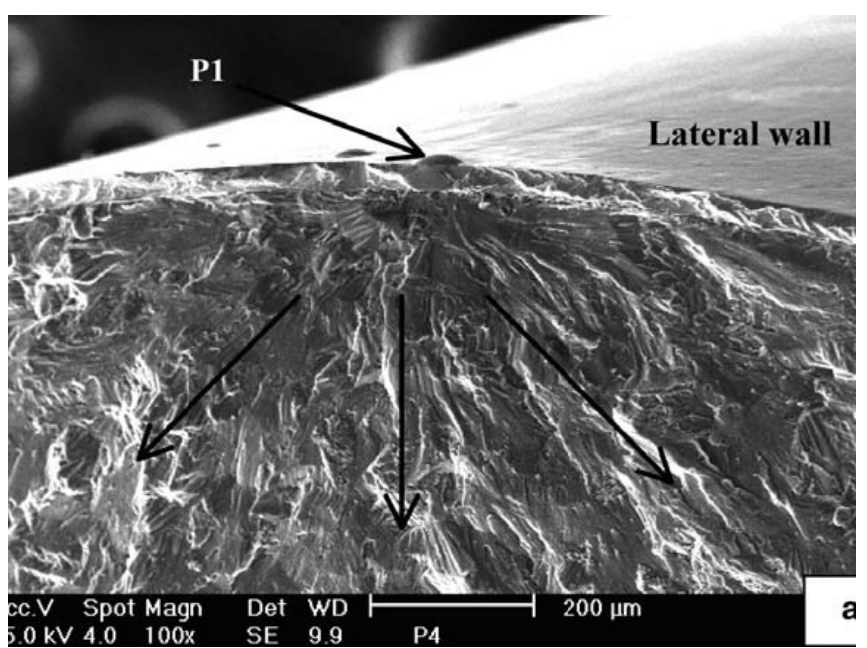

(b)

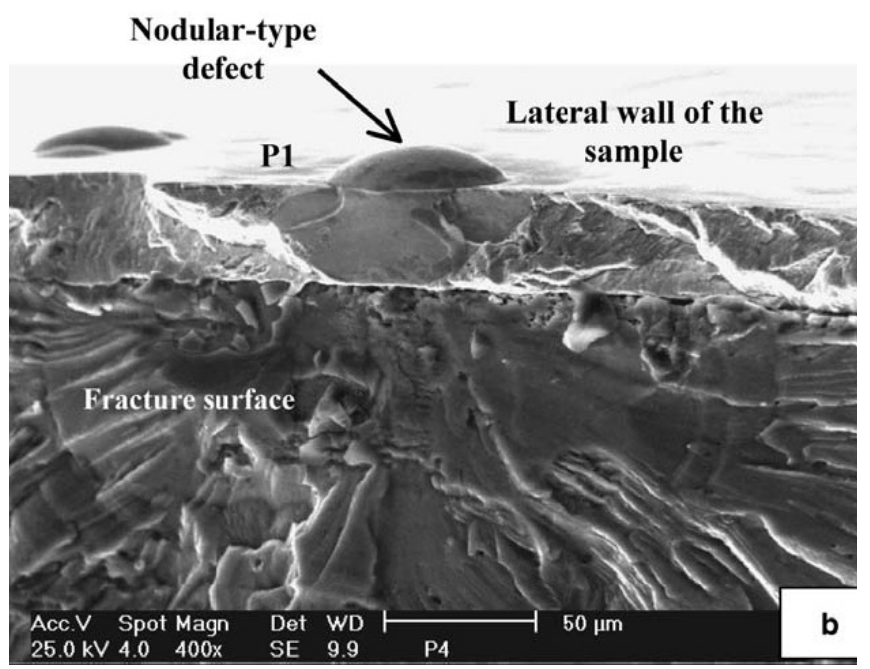

Fig. (6). Micrographs showing the association of the crack initiation site with a nodular surface defect in a 7075-T6 electroless Ni-Pcoated sample failed at an alternating stress of $219 \mathrm{MPa}$ [40]. smooth and notched samples was studied at $2 \times 10^{5}$ cycles. The presence of the coating lowered the fatigue resistance of the base material and a similar decrease, in the range between 12 to $14 \%$, was found for the smooth and the notched samples as well (Table 1). The phenomenon was investigated by numerical modelling, as reported in the next section. Most recent studies on PVD coated Ti-6Al-4V alloy, conducted by Costa et al. by means of axial $(R=0.1)$ fatigue tests [38], confirmed this behavior for TiN, $\mathrm{CrN}$ and $\mathrm{WC}: \mathrm{H}$ DLC PVD coatings. Results for the base material and the three coatings are reported in Fig. (7). At $1 \times 10^{7}$ cycles, TiN coated specimens presented a significant drop in the fatigue maximum axial stress of $50 \%$, while the loss was contained for $\mathrm{CrN}$ and WC:H DLC samples, with a $16.6 \%$ and a $5.5 \%$ reduction respectively. Coating maximum deposition temperatures were similar for the three processes (about $450{ }^{\circ} \mathrm{C}$ ), but the heat load steps were varied according to the different coating procedures.

Finally, the study by Braun et al. [41] on the oxidation and fatigue behavior of $\gamma$-TiAl intermetallic alloy for high temperature applications coated with high power impulse magnetron sputtered (HIPIMS) CrAlYN/CrN nanoscale multilayer coatings. The coatings were effective in protecting the substrate from oxidation at 850 and $900{ }^{\circ} \mathrm{C}$. However, the fatigue strength $(R=-1)$ of coated alloy thermally exposed to air at $850^{\circ} \mathrm{C}$ for $300 \mathrm{~h}$ was significantly reduced in comparison to that of the as-received material from about $730 \mathrm{MPa}$ down to about $660 \mathrm{MPa}$.

Based on the reported results, it is important to stress that the fatigue behavior of thin hard-coated light alloys has been studied even less than that of coated steels. This allows for a plenty of research opportunities, being also considered that most of these materials are used for advanced structural applications. By summing up the literature work, it can be concluded that some good results were found for aluminium alloys tested under rotating bending in both laboratory air and $\mathrm{NaCl}$ solution. However, the good corrosion-fatigue properties guaranteed by some coatings should be investigated more extensively for a broader range of light base materials.

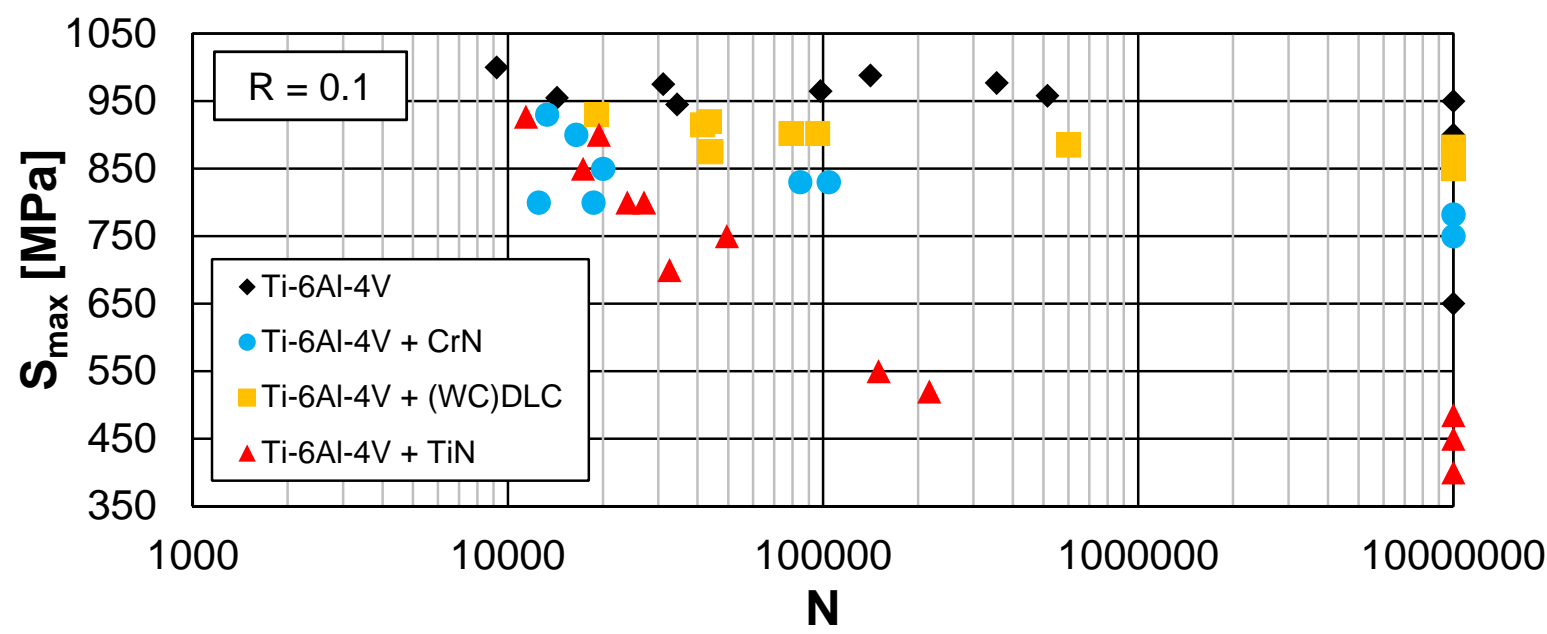

Fig. (7). Maximum stress $v s \mathrm{~N}{ }^{\circ}$ of cycles for uncoated, CrN, WC:H DLC and TiN PVD coated Ti-6Al-4V axial fatigue specimens $(R=0.1)$, adapted from data presented in [38]. 
The worst results were collected for aluminium and titanium alloys coated at high deposition temperatures, confirming that this is a key parameter to account for if one aims to improve the mechanical strength of this class of structural materials by depositing wear- and corrosionresistant coatings. Heat effect is particularly important for aluminium high performance light alloys, such as 7075-T6, which have relatively low ageing temperatures $\left(121{ }^{\circ} \mathrm{C}\right)$. Low temperature PVD coatings, such as $\mathrm{WC} / \mathrm{C}$, show limited reduction of fatigue performances, if not beneficial effects, with their maximum deposition temperature of about $200{ }^{\circ} \mathrm{C}$. Material modifications due to thermal effects are not negligible anyway, but their contribution for low temperature PVD processes is likely less detrimental with respect to high temperature PVD and CVD coatings. For this reason, TiN PVD deposition process showed the highest decreases in terms of fatigue behavior, both on aluminium and titanium substrates. Fatigue performances of TiN coated 7075-T6 specimens could be somehow recovered with appropriate post heat treatments.

\section{NUMERICAL MODELS}

The corrosion-fatigue behavior of thin hard-coated components has not been numerically studied up until now. Also, numerical models able to predict the fatigue life are almost missing in the literature. This section recalls the main results achieved by the Authors within this area.

In $[17,18]$, Baragetti et al. developed a theoreticalnumerical model to predict the fatigue life of thin hardcoated components. By simulating an initial defect in the FE model of a coated component and by introducing the residual stress field generated by the coating deposition process, the fatigue crack growth under specified loading conditions was simulated in a discrete way to calculate the number of cycles necessary for each crack depth increment to occur. The applied stress intensity factor range $\Delta K_{\text {app }}$ - including the residual stress effect - was calculated by means of nodal displacement extrapolation at the crack tip and microstructural fracture mechanics was applied to evaluate the threshold stress intensity factor range $\Delta K_{\mathrm{th}}$. The hardness distribution in the surface layers of the coated component must also be known to complete the calculation procedure consisting of verifying whether the applied stress intensity factor range is higher than the threshold stress intensity factor range and of determining the crack propagation rate by formula. In $[17,18]$, the procedure was applied to the CrNcoated 2205 duplex stainless steel and H11 tool steel samples tested under four-point bending fatigue previously mentioned. The numbers of cycles until failure calculated were in good accordance with the experimental results showing errors lower than $14 \%$.

Remarkable results were also collected by applying the procedure to transmission spur gears for racing motorcycles [43]. The growth of a semi-elliptical surface crack placed at tooth root was simulated for both steel and titanium uncoated and PVD-coated gears (Fig. 8). The opportunity to lower the component mass by using titanium alloy rather than steel by verifying the fatigue resistance in the presence of the coating was addressed. The graph of Fig. (9) shows the critical crack depths of the coated and the uncoated gears with the (a)

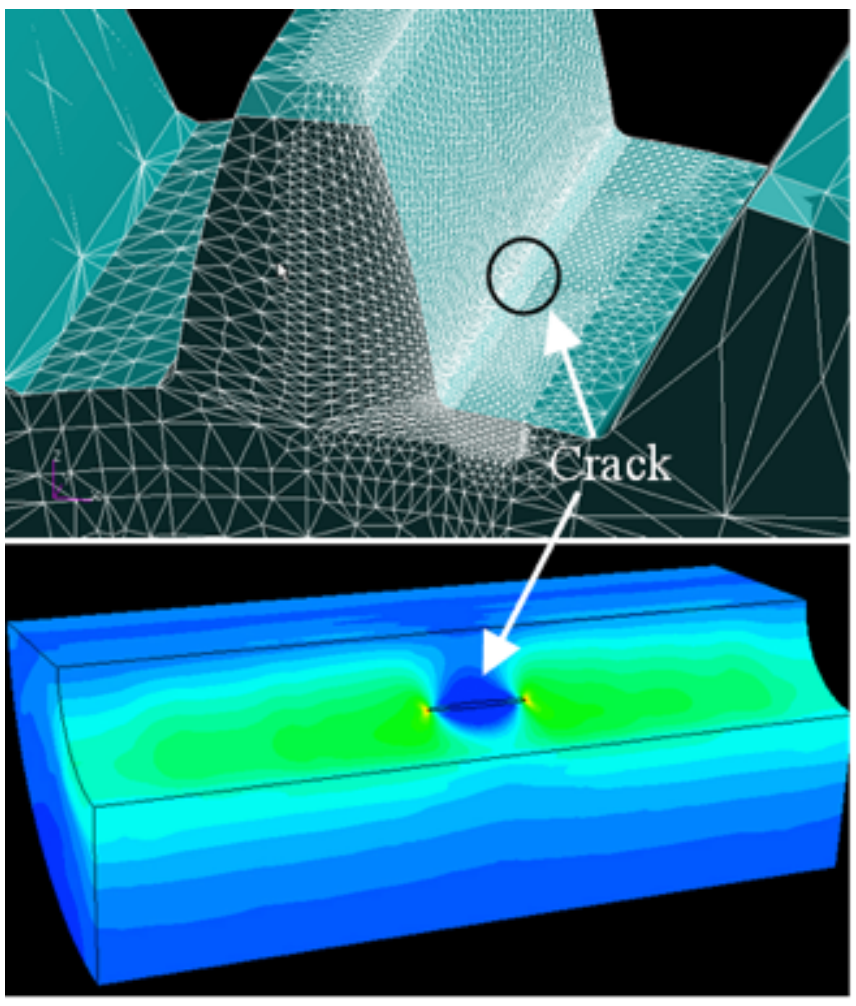

(b)
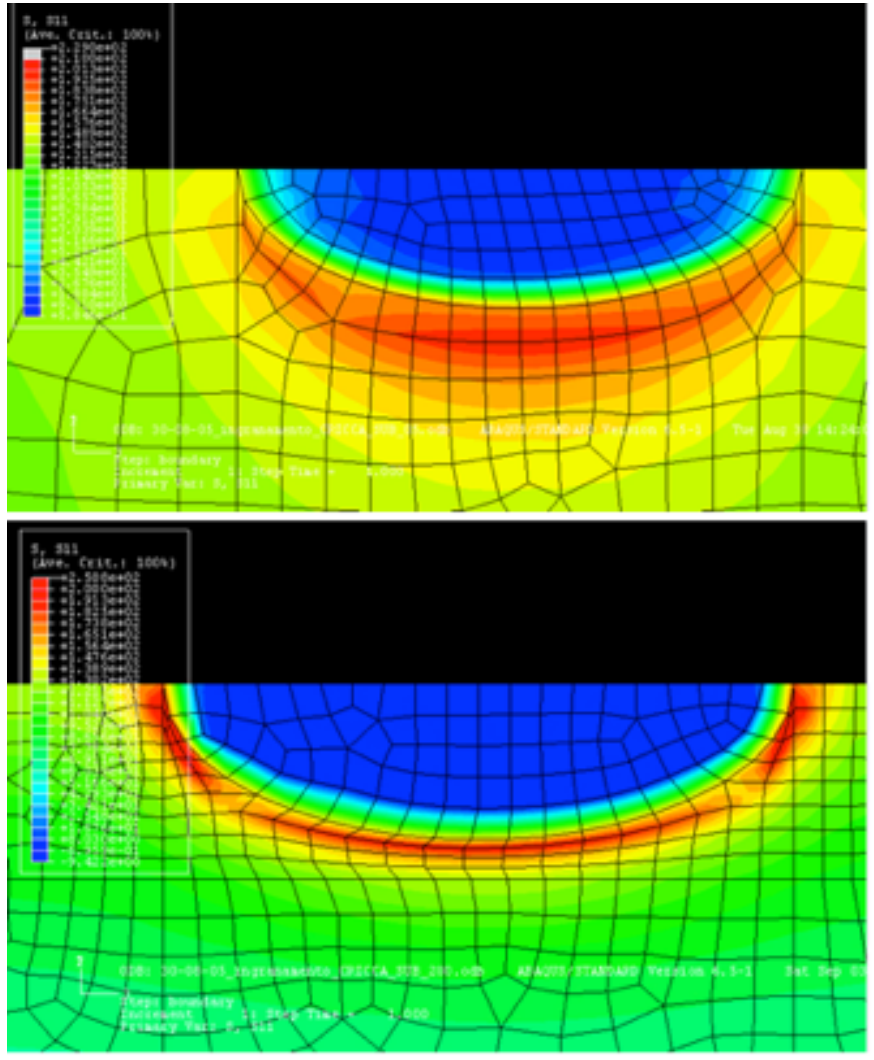

Fig. (8). (a) Mesh appearance at tooth root and stress state around the defect area and (b) stress contour map at the propagating fronts of the 5 and $200 \mu \mathrm{m}$-deep cracks in a PVD-coated steel gear studied in [43]. 


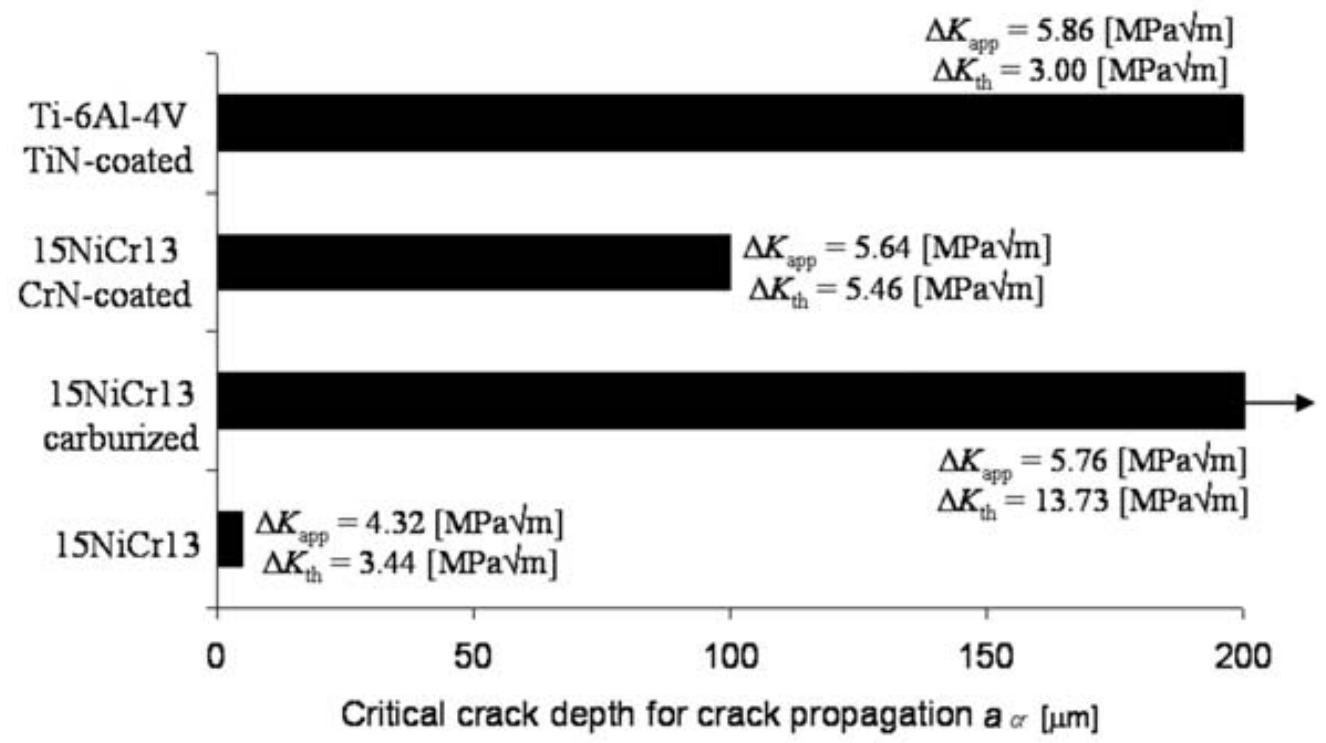

Fig. (9). Critical crack depths of the coated and the uncoated steel and titanium gears studied in [43].

indication of the threshold and the applied stress intensity factors ranges. The relatively low $\Delta K_{\text {app }}$ resulting from both the high residual compressive stresses in the surface layers and the lower substrate elastic modulus made it reasonable to compare the fatigue behavior of the coated titanium gear with that of the carburized steel one. As a matter of fact, the lower stress intensity factor ranges produced slower crack growth rates in the coated titanium gear - say 432,220 load cycles to produce a $200 \mu \mathrm{m}$-deep crack in the coated titanium gear $v s$ 154,160 in the coated steel one.

The crack growth model, developed for thin coated components in [43], was successfully extended in $[44,45]$ to predict the rolling contact fatigue (RCF) behavior of uncoated WC/C-coated AISI 3415 and Ti-6Al-4V racing motorcycle spur gears. The model was applied to a FE analysis, consisting in a global model of the pinion and the driven gear of a sixth speed high performance spur gear, simulating the contact problem, integrated with a submodel for the crack propagation modeling. The results of the models, which proved the $\mathrm{WC} / \mathrm{C}$ coating to be beneficial for RCF behavior, were compared with actual AISI $3415 \mathrm{WC} / \mathrm{C}$ coated and uncoated gears subdued to RCF testing. The final damage of the tooth was obtained by measuring the tooth profile, and showed coherent results if compared to the FE outcome.

In [42], the stress distribution underneath and the stress state in the coating of the notched and smooth uncoated and TiN-coated Ti-6Al-4V samples mentioned in the previous section were numerically determined to achieve better understanding of the experimental results. Threedimensional FE models of the samples accounting for the residual stress distribution due to the coating deposition process were generated (Fig. 10a). Furthermore, four different values of coating elastic modulus, say 100, 200, 300 and $400 \mathrm{GPa}$, were considered in the models to verify the influence of this parameter on the local stress state in the coating and in the bulk material and hence to evaluate the opportunity to adjust its value to increase the performance of the coating in the presence of fatigue loads and notches.
Typical values of elastic modulus of TiN can actually fall within the range $300-400 \mathrm{GPa}[7,14]$. It was pointed out that, regardless of the presence of the notch, the subsurface tensile stresses balancing out the residual stress distribution could have contributed to produce a localized plasticization underneath after the application of the bending load. Fig. (10b) shows the superposition of the numerical stress trend on the fracture surface of a smooth-coated sample.

The crack nucleation could actually have occurred where the calculated maximum tensile stresses were present. It was also found that only the local stress state within the coating was affected by the variation of the coating elastic modulus. In fact, similar stress distributions between the smooth- and notched-coated samples were found. This was believed to have contributed to the similar fatigue behavior observed experimentally. High resultant tensile stresses were achieved in the coating in the two notched samples having the higher coating elastic moduli. By contrast, the less stiff ones kept being under compression after loading regardless of the presence of the notch. As a matter of fact, compressive stresses can keep cracks already present in the coating closed or prevent their formation.

With regard to the reported review of numerical studies on the fatigue behavior of thin hard-coated components, it can be concluded that, in spite of the first good results, the numerical study of the fatigue behavior of components coated with thin hard corrosion-resistant coatings has not been developed enough yet. In fact, the number of papers dealing with the fatigue life prediction of coated components is very limited. Coated light alloys would deserve particular attention in respect of the opportunity to reduce the mass of mechanical components without affecting or even by increasing their fatigue strength. In fact, more and more accurate models should be proposed to capture as accurately as possible all the features characterizing the coating and material behaviors and the effects of the deposition process. The experimental validation of the models would be fundamental from this viewpoint. Furthermore, the experimental research activity could become more effective if planned according to the results of the models. 
(a)

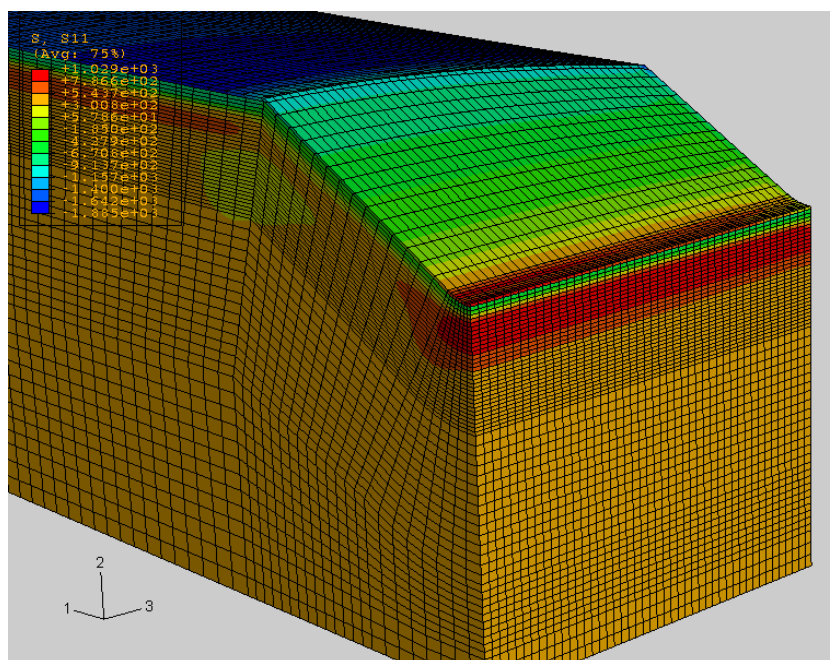

(b)

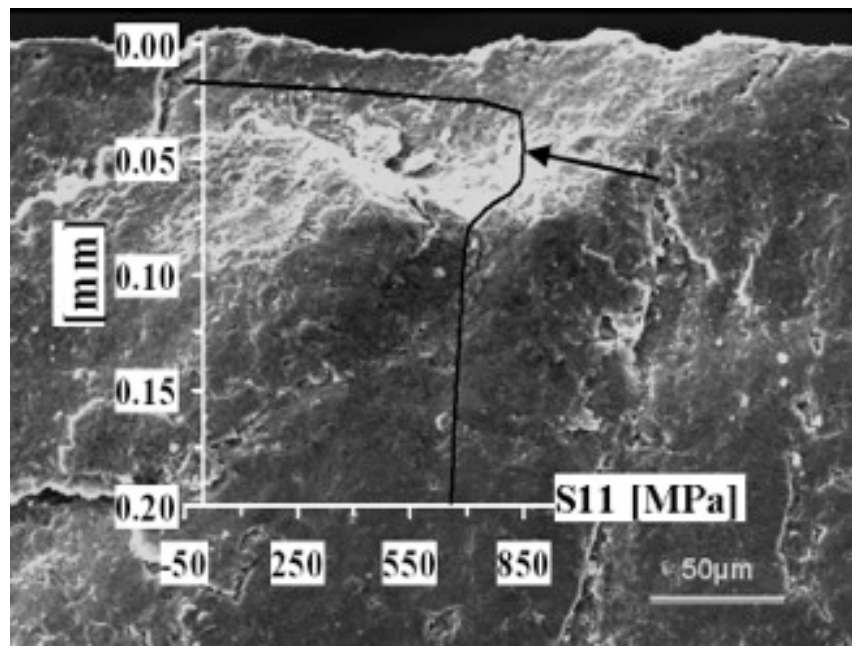

Fig. (10). (a) Axial stress contour map in the submodel of a notched-coated Ti-6Al-4V sample and (b) superposition of the numerical stress gradient on a micrograph of the crack initiation site in a coated smooth Ti-6Al-4V sample. The arrow points at the maximum tensile stress placed within the nucleation area [42].

Indeed, the availability of easy-to-apply numerical models would be really important for machine designers, who would account on fast and reliable tools to save working time particularly at project beginning stage. The integration between structural engineering and corrosion science through proper multiphysics approach, by developing numerical procedures to foresee the corrosion-fatigue behavior of thin hard coated components could constitute a remarkable step forward for many applications.

\section{SUMMARY}

An extended review on the state of the art on the mechanical behavior of thin hard PVD and CVD coatings for corrosion protection has been presented, including some key behaviors, which may not be sufficiently deepened in the previous research works. Good results in terms of fatigue strength, due to the generation of high surface residual compressive stresses by the deposition process, have been observed especially at high number of cycles, leading in some cases to subsurface crack initiation.

This positive fatigue behavior induced by thin hard coatings has been in some cases overshadowed by detrimental effects in terms of fatigue strength at high limiting stresses. The reason may be found in a different mechanical behavior and crack nucleation mechanism in fatigue strength at a low limiting number of cycles, due to the higher strain induced in the coating. Other critical aspects of PVD and CVD coatings include undesired fatigue strength reduction, observed for high-temperature deposition processes, which have probably severely modified the substrate properties of high strength-to-mass ratio alloys.

In addition, new models for crack propagation and fatigue life evaluation in terms of number of cycles have been presented, including studies on actual coated mechanical components, thus extending the analysis capabilities in the design of thin-coated, corrosion resistant components.

In conclusion, the research on thin hard coatings has to be broadened along some crucial paths in order to provide reliable knowledge for components design. In particular, the expertise on the fatigue and corrosion fatigue behavior of PVD and CVD coated steels and light alloys has to be improved, since a clear dependence of these key design performances from the number of cycles and the deposition process has been deeply highlighted.

In this perspective, analyses on specific substrate-coating couplings have to be carried on, considering the thin layer morphology, the deposition temperature, the limiting stress and the number of cycles for which the components have to be engineered. In particular, the dynamics of the coating failure at high stresses, which often cause detrimental fatigue effects, must be investigated, considering also the different substrate characteristics between steels and other alloys.

By looking at the literature data, $\mathrm{TiN}$ and $\mathrm{CrN}$ coatings have shown the best outcomes in terms of fatigue resistance, due to high post-process residual compressive stresses. Such advantages are likely limited to substrates that do not show significant modifications due to the high temperature processes. Especially for light alloys, a reduction of the negative effects of high deposition temperatures is expected by the adoption of low temperature PVD coatings, such as $\mathrm{WC} / \mathrm{C}$ and DLC.

The numerical study of the fatigue behavior of components coated with thin hard corrosion-resistant coatings has to be improved, providing the machine designer with significant tools in order to quantify at least the mechanical effects which affect the fatigue strength of thin coated components.

Furthermore, a massive experimentation in terms of corrosion fatigue is still needed in order to quantify the effects on the coated material related to the interaction between the aggressive environment and the fatigue behavior. A comparison of the corrosion fatigue experimental effects with the numerical models and the experimentation in a neutral environment could hence lead to the identification and the decoupling of the chemical and mechanical driving forces involved in the process. 


\section{CONFLICT OF INTEREST}

The authors confirm that this article content has no conflict of interest.

\section{ACKNOWLEDGEMENTS}

The following work has been conducted by the Authors' own funding and effort.

\section{REFERENCES}

[1] Baragetti S, Tordini F. A review of the fatigue behavior of components coated with thin hard corrosion-resistant coatings. Open Corr J 2011; 4: 9-17.

[2] Navinšek B, Panjan $P$, Milošev I. Industrial applications of $\mathrm{CrN}$ (PVD) coatings, deposited at high and low temperatures. Surf Coat Technol 1997; 97:182-91.

[3] Panjan P, Cvahte P, Čekada M, Navinšek B, Urankar I. PVD CrN coating for protection of extrusion dies. Vacuum 2001; 61:241-4.

[4] Navinšek B, Panjan P, Gorenjak F. Improvement of hot forging manufacturing with PVD and DUPLEX coatings. Surf Coat Technol 2001; 137:255-64.

[5] Su YL, Yao SH, Wei CS, Kao WH, Wu CT. Comparison of wear, tensile, and fatigue properties of PVD coated materials. Mater Sci Tech 1999; 15: 73-7.

[6] Cunha L, Andritschky M. Residual stress, surface defects and corrosion resistance of CrN hard coatings. Surf Coat Technol 1999; 111: 158-62.

[7] Mendibide C, Steyer P, Fontaine J, Goudeau P. Improvement of the tribological behavior of PVD nanostratified TiN/CrN coatings - An explanation. Surf Coat Technol 2006; 201: 4119-24.

[8] Angelini E, d'Agostino R, Fracassi F, Grassini S, Rosalbino F. Surface analysis of PECVD organosilicon films for corrosion protection of steel substrates. Surf Interface Anal 2002; 34: 155-59.

[9] He JL, Chu CH, Wang HL, Hon MH. Corrosion protection by PECVD-SiOx as a top coating on TiN-coated steel. Surf Coat Technol 1994; 63(1): 15-23.

[10] Moretti G, Guidi F, Canton R, Battagliarin M, Rossetto G. Corrosion protection and mechanical performance of $\mathrm{SiO} 2$ films deposited via PECVD on OT59 brass. Anti-Corr Meth Mater 2005; 52(5): 266-75.

[11] Walker M, Meermann F, Schneider J, et al. Investigations of plasma polymerized barrier films on polymeric materials. Surf Coat Technol 2005; 200(1-4): 947-52.

[12] Zajiččková L, Janča J, Peřina V. Characterization of silicon oxide thin films deposited by plasma enhanced chemical vapor deposition from octamethylcyclotetrasiloxane/oxygen feeds. Thin Solid Films 1999; 338(1-2): 49-59.

[13] Guu YH, Hocheng H. Improvement of fatigue life of electrical discharge machined AISI D2 tool steel by TiN coating. Mater Sci Eng 2001; A318: 155-62.

[14] Puchi-Cabrera ES, Matínez F, Herrera I, Berríos JA, Dixit S, Bhat D. On the fatigue behavior of an AISI 316L stainless steel coated with a PVD TiN deposit. Surf Coat Technol 2004; 182: 276-86.

[15] Puchi-Cabrera ES, Staia MH, Ochoa-Perez EA, et al. Fatigue behavior of a 316L stainless steel coated with a DLC film deposited by PVD magnetron sputter ion plating. Mater Sci Eng AStruct Mater Prop Microstruct Process 2010; 527(3): 498-508.

[16] Baldissera P, Cavalleri S, Marcassoli P, Tordini F. Study of the Effect of DCT and PVD treatments on the fatigue behaviour of AISI 302 stainless steel. Key Eng Mater 2010; 417-418: 49-52.

[17] Baragetti S, La Vecchia GM, Terranova A. Fatigue Behavior and FEM modelling of thin-coated components. Int J Fat 2003; 25: 1229-38.

[18] Baragetti S, La Vecchia GM, Terranova A. Variables affecting the fatigue resistance of PVD-coated components. Int J Fat 2005; 27(10-12): 1541-50.

[19] Baragetti S, Tordini F. Fatigue resistance of PECVD coated steel alloy. Int J Fat 2007; 29: 1832-8.

[20] Saini BS, Gupta VK. Effect of WC/C PVD coating on fatigue behaviour of case carburized SAE8620 steel. Surf Coat Technol 2010; 205:511-8.
Ortiz-Mancilla MJ, Mariño-Berroterán C, Berríos-Ortiz JA, Mesmacque G, Puchi-Cabrera ES. Effect of a thin hard chromium coating on fatigue behaviour of 4140 steel. Surf Eng 2004; 20(5): $345-52$.

[22] Kim KR, Suh CM, Murakami RI, Chung CW. Effect of intrinsic properties of ceramic coatings on fatigue behaviour of $\mathrm{Cr}-\mathrm{Mo}-\mathrm{V}$ steels. Surf Coat Technol 2003; 171: 15-23.

[23] Suh CM, Hwang BW, Murakami RI. Behaviours of residual stress and high-temperature fatigue life in ceramic coatings produced by PVD. Mater Sci Eng 2003; A343: 1-7.

[24] Merlo AM. The contribution of surface engineering to the product performance in the automotive industry. Surf Coat Technol 2003; 174-(175): 21-6.

[25] Vetter J, Barbezat G, Crummenauer J, Avissar J. Surface treatment selections for automotive applications. Surf Coat Technol 2005; 200: 1962-68.

[26] Gåhlin R, Larsson M, Hedenqvist P. ME-C:H coatings in motor vehicles. Wear 2001; 249: 302-9.

[27] Treutler CPO. Industrial use of plasma-deposited coatings for components of automotive fuel injection systems. Surf Coat Technol 2005; 200: 1969-75.

[28] Bobzin K, Bagcivan N, Goebbels N, et al. Lubricated PVD CrAlN and $\mathrm{WC} / \mathrm{C}$ coatings for automotive applications. Surf Coat Technol 2009; 204: 1097-101.

[29] Wellman RG, Nicholls JR. Erosion, corrosion and erosioncorrosion of EB PVD thermal barrier coatings. Tribol Int 2008; 41 : 657-62.

[30] Feuerstein A, Kleyman A. Ti-N multilayer systems for compressor airfoil sand erosion protection. Surf Coat Technol 2009; 204: 10926.

[31] Love CA, Cook RB, Harvey TJ, Dearnley PA, Wood RJK Diamond like carbon coatings for potential application in biological implants - a review. Tribol Int 2013; 63: 141-50.

[32] Lamastra FR, Leonardi F, Montanari R, Casadei F, Valente T, Gusmano G. X-ray residual stress analysis on $\mathrm{CrN} / \mathrm{Cr} / \mathrm{CrN}$ multilayer PVD coatings deposited on different steel substrates. Surf Coat Technol 2006; 200: 6172-5.

[33] Holmberg K, Ronkainen H, Laukkanen A, et al. Residual stresses in TiN, DLC and MoS2 coated surfaces with regard to their tribological fracture behaviour. Wear 2009; 267: 2142-56.

[34] Oskouei RH, Ibrahim RN. The effect of a heat treatment on improving the fatigue properties of aluminium alloy 7075-T6 coated with TiN by PVD. Procedia Eng 2011; 10: 1936-42.

[35] Baragetti S, Lusvarghi L, Bolelli G, Tordini F. Fatigue behaviour of 2011-T6 aluminium alloy coated with PVD WC/C, PA-CVD DLC and PE-CVD SiOx coatings. Surf Coat Technol 2009; 203: 3078-87.

[36] Baragetti S, Gerosa R, Villa F. Fatigue behaviour of thin coated Al 7075 alloy with low temperature PVD coatings. Key Eng Mater 2014; 577-(578): 221-4.

[37] Baragetti S, Gerosa R, Rivolta B, Silva G, Tordini F. Fatigue behavior of foreign object damaged 7075 heat treated aluminum alloy coated with PVD WC/C. Procedia Eng 2011; 10: 3375-80.

[38] Costa MYP, Venditti MLR, Cioffi MOH, Voorwald HJC Guimarães VA, Ruas R. Fatigue behavior of PVD coated Ti-6Al4V alloy. Int J Fatigue, 2011; 33: 759-65.

[39] Puchi-Cabrera ES, Staia MH, Lesage J, et al. Fatigue behavior of AA7075-T6 aluminum alloy coated with ZrN by PVD. Int J Fat 2008; 30: 1220-30.

[40] Puchi-Cabrera ES, Villalobos-Gutiérrez C, Irausquín I, La BarberaSosa J, Mesmacque G. Fatigue behavior of a 7075-T6 aluminum alloy coated with an electroless Ni-P deposit. Int J Fatigue 2006; 28: $1854-66$

[41] Braun R, Schulz U, Leyens C, Hovsepian PE, Ehiasarian AP. Oxidation and fatigue Behavior of $\gamma$-TiAl coated with HIPIMS CrAlYN/CrN nanoscale multilayer coatings and EB-PVD thermal barrier coatings. Int J Mater Res 2010; 101(5): 648-56.

[42] Baragetti S, Tordini F. A Numerical study of the fatigue behaviour of notched PVD-coated Ti-6Al-4V. Struc Durab Health Monit 2007; 3(3): 165-76.

[43] Baragetti S. Fatigue resistance of steel and titanium PVD coated spur gears. Int J Fat 2007; 29: 1893-903.

[44] Baragetti S, Cavalleri S, Tordini F. A numerical and experimental study of the RCF behaviour of PVD-coated spur gears. Key Eng Mater 2011; 452(453): 589-92. 
[45] Baragetti S, Cavalleri S, Tordini F. A numerical method to predict the RCF behaviour of PVD-coated Transmission gears and experimental results. Procedia Eng 2011; 10: 1485-90

[46] Moinereau D, Brochard J, Guichard D, Bhandari S, Sherry A, France C. Local approach of cleavage fracture applied to a vessel with subclad flaw. A benchmark on computational simulation. ASME Publ PVP 1996; 324: 267-76.

[47] Smith RW. Computer simulation of intergranular stress corrosion cracking via hydrogen embrittlement. Modelling and simulation in materials science and engineering. Mater Sci Eng 2000; 8(4): 62948.

[48] Dejun M, Kewei X, Jiawen H. Numerical simulation for determining the mechanical properties of thin metal films using depth-sensing indentation technique. Thin Solid Films 1998; 323:183-7.

[49] Souza RM, Mustoe GGW, Moore JJ. Finite-element modeling of the stress and fracture during the indentation of hard elastic films on elastic-plastic aluminum substrates. Thin Solid Films 1999; 355356: $303-10$.

(C) Baragetti and Villa; Licensee Bentham Open.

This is an open access article licensed under the terms of the Creative Commons Attribution Non-Commercial License (http://creativecommons.org/licenses/ by-nc/3.0/) which permits unrestricted, non-commercial use, distribution and reproduction in any medium, provided the work is properly cited. 